\title{
Lightning Protection Design for Small Riverboats Using the FDTD Method
}

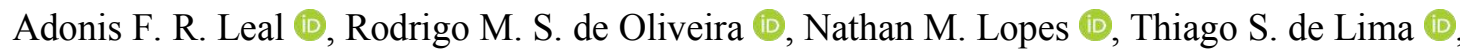 \\ Eduardo R. Ferreira (D), Nilton Rodolfo N. M. Rodrigues (1) \\ Federal University of Pará,Brazil, adonisleal@ufpa.br,rmso@ufpa.br,nathan99ml@gmail.com, \\ thiagosdl13@gmail.com,eduardo.ferreira@itec.ufpa.br,niltonrodolfo@gmail.com
}

\begin{abstract}
The Amazon region has high lightning occurrence rates, with many lightning hot spots. Different rivers cross the Amazon rainforests and the people that live there use these rivers as roads to go from one place to another. Every year, lightning deaths are reported in the Brazilian Amazon region. In 2018, a lightning discharge struck a small riverboat, which killed 4 people and injured 5 in the North region of Brazil. In this study, we investigate lightning fatalities in Amazon rivers and compute electric field distribution in a small riverboat due to a lightning strike using the finite-difference time-domain (FDTD) method. The results show that the electric field produced inside the boat is large enough to cause air breakdown. Additionally, we propose a cost-effective method to improve lightning safety for people that use small boats in the Amazon region.
\end{abstract}

Index Terms - riverboat lightning protection, FDTD method, lightning fatalities in Amazon rivers

\section{INTRODUCTION}

Lightning is a real threat to human beings in the Brazilian Amazon region. More than 77 million lightning strike the Brazilian territory every year according to the Brazilian National Institute for Space Research (INPE) [1]. The tropical zone is the region of the planet with the highest occurrence levels of cumulonimbus clouds, which are the main source of lightning on Earth [2]. Brazil is one of the most extensive countries in the tropical zone, that is, it becomes the main target of lightning occurrence. The majority of Brazilian states with higher lightning rates are located in the Brazilian Amazon region (Acre, Amapá, Amazonas, Maranhão, Mato Grosso, Pará, Rondônia, Roraima, and Tocantins). Figure 1 shows the lightning density map in the Brazilian Amazon region calculated with STARNET [3] (reprocessed data), for the period between the years of 2013 and 2017.

According to Ferreira et al. [4], 119 people were killed by lightning in the Amazon region of Brazil from 2009 to 2019 . They found that $60 \%$ of lightning fatalities occurred in rural areas and mostly occurred with men (78\%). The death rate in the Amazon region of Brazil was found to be about 4 deaths per million habitants, higher than in developed countries [5], [6]. Ferreira et al. [4] showed a case study in which 4 people were killed and 5 were injured due to a lightning strike in a boat that was transporting children to schools in communities in the state of Acre, Brazil. 


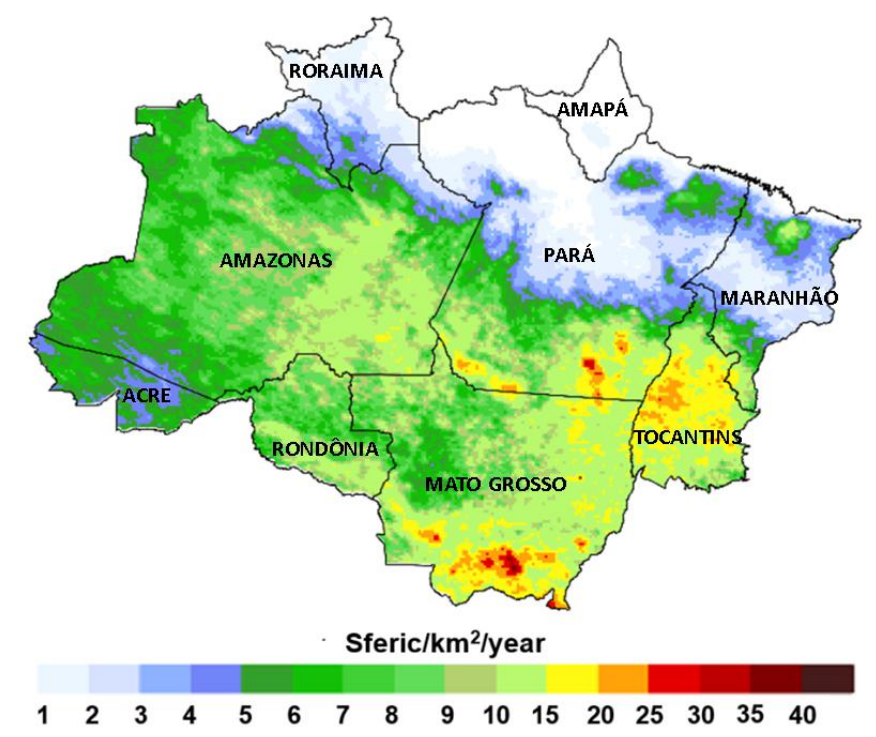

Fig. 1. Annual sferics density in the Brazilian Amazon region (average 2013-2017). Source: STARNET [3].

The lightning protection of riverboats or small watercrafts in general is a challenging task. Their small dimensions, the different types of materials used in their construction, and the relatively poor electricity conduction of river water are some of the issues faced in the lightning protection design of small riverboats in the Amazon region. According to Thomson [7], about 3\% or more of southwest Florida boats have their marine electronics damaged due to direct or indirect lightning strikes. Unfortunately, there is no statics for lightning related damages on small riverboats for the Brazilian Amazon region. In the U.S, the lightning protections of boats are defined by different agencies including the American Boat and Yacht Council, the Coast Guard, the Florida Sea Grant, and the National Fire Protection Association. However, in Brazil, to the best of our knowledge, there is no guidance for lightning protection for small watercrafts.

Currently, there are significant efforts in lightning protection of electric power systems [8], telecommunication systems [9], [10], and structures [11]. However, there is limited information in the scientific literature on lightning protection of boats or small vessels in general. There are studies on large vessels such as ships. For instance, Nicolopoulou et al. [12] investigated the lightning protection zone in ships through impulse voltage tests on a scaled-down ship model. They found that the international instructions of marine regulations are in most cases insufficient. Nicolopoulou et al. [13] studied lightning-induced overvoltages in the electric network of a ship using the CST Cable Studio environment. They simulated lightning strikes in different parts of the ship and evaluated the induced overvoltage. Their major conclusion concerns improving the immunity testing of marine equipment.

In this work, we extend the analyses of Ferreira et al. [4] regarding the case study and include a survey regarding lightning safety in boats in the Amazon Region rivers (see the Appendix) to understand if the locals are aware of how dangerous lightning can be. Additionally, for the first time, we perform a numerical study of the electric fields inside the watercraft due to a direct lightning strike 
to assess risks to which passengers are subjected to. Subsequently, we design and optimize the performance of a lightning protection system for a common riverboat in the Amazon region by balancing the produced transient magnetic fields. Results are obtained by solving Maxwell's equations numerically with the FDTD method. Finally, it is shown that the proposed optimized lightning protection systems can improve the lightning safety of the riverboat occupants during thunderstorms.

\section{Methodology}

The riverboats are widely used in the rivers of the Amazon region, and they are very important for the locals. These riverboats are used in the economic activities of the region, as well as in the transportation of people from one city/village to another city/village. Hence, we tried to identify how the boat construction process takes place. Most of the riverboats (called "Catraia" by the locals) in the region are small and can support 5 to 25 occupants. Some boats have no roof, consisting only of the structure responsible for floating. The riverboat roofs are mostly composed of a layer of wood and a thin layer of metal. In some cases, an additional layer of plastic is added. In our simulations, we considered the riverboat with the roof made by a single layer of metal, the same in which 4 people died and 5 were injured due to a lightning strike in the state of Acre, Brazil (see Fig. 2).

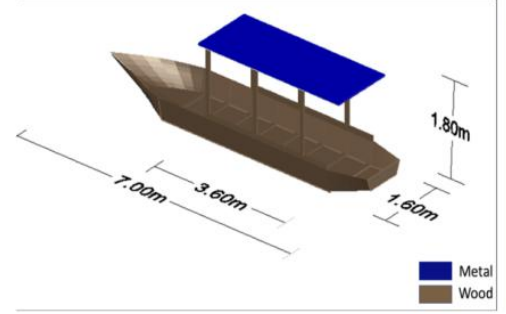

(a)

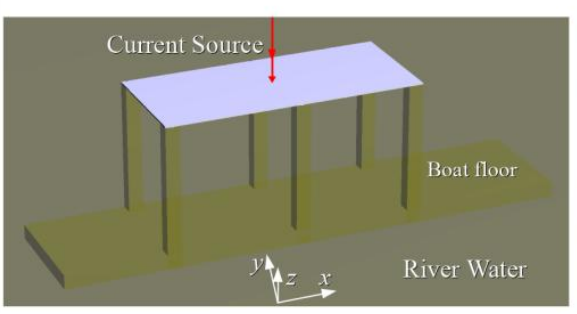

(b)

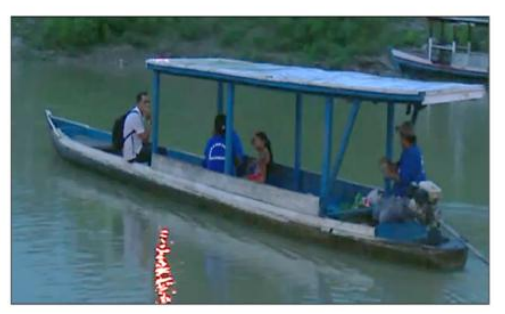

(c)

Fig. 2. Catraia, a common small riverboat found in the Brazilian Amazon Rivers: (a) 3D model of the riverboat that was used as a reference for conceiving FDTD representation, (b) FDTD computational representation of the Catraia on the river water, which was used for computing of E-fields and (c) photograph of a riverboat that the locals use in the region.

\section{A. The FDTD Method and Riverboat Modeling}

1) Review of the FDTD method: Maxwell's equations, which describe the propagation of electromagnetic waves in lossy, isotropic, and non-dispersive media, in their differential form in the time domain are

and

$$
\nabla \times \vec{E}=-\mu \frac{\partial \vec{H}}{\partial t}
$$

$$
\nabla \times \vec{H}=\varepsilon \frac{\partial \vec{E}}{\partial t}+\vec{J}
$$


in which $\vec{H}, \vec{E}$ and $\vec{J}=\sigma \vec{E}$ are magnetic field (A/m), electric field (V/m), and electrical current density $\left(\mathrm{A} / \mathrm{m}^{2}\right)$, respectively. The constants $\varepsilon, \mu$, and $\sigma$ are, respectively, the electric permittivity $(\mathrm{F} / \mathrm{m})$, and magnetic permeability $(\mathrm{H} / \mathrm{m})$, and electric conductivity $(\mathrm{S} / \mathrm{m})$. When expanded into Cartesian coordinates, (1) and (2) generate six scalar equations. For example, the $x$-components of magnetic and electric fields can be calculated, respectively, using

$$
\frac{\partial H_{x}}{\partial t}=\frac{1}{\mu}\left(\frac{\partial E_{y}}{\partial z}-\frac{\partial E_{z}}{\partial y}\right)
$$

and

$$
\frac{\partial E_{x}}{\partial t}=\frac{1}{\varepsilon}\left(\frac{\partial H_{z}}{\partial y}-\frac{\partial H_{y}}{\partial z}-\sigma \mathrm{E}_{x}\right)
$$

In 1966, Kane Yee [14] developed a discretization model based on finite difference approximations for solving Maxwell's equations: the FDTD (Finite-Difference Time-Domain) method. The analysis space is numerically represented by using a set of Yee cells, where the field vectors are positioned in order to satisfy the circulations in (1) and (2). The Yee cell has edges measuring $\Delta x, \Delta y$, and $\Delta z$. Positions over the domain are indexed using integer indexes $i, j$, and $k$. The physical position of the cell reference node in the domain is given by $x=i . \Delta x, y=j . \Delta y$, and $z=k . \Delta z$. The electric field is calculated at time $t=n . \Delta t$ and $\vec{H}$ is computed at $t=(n+1 / 2) . \Delta t$. Therefore, (3) and (4) can be approximated by

$$
\left.H_{x}\right|_{i, j+\frac{1}{2}, k+\frac{1}{2}} ^{n+\frac{1}{2}}=\left.H_{x}\right|_{i, j+\frac{1}{2}, k+\frac{1}{2}} ^{n-\frac{1}{2}}+\frac{\Delta t}{\mu}\left[\frac{\left.E_{y}\right|_{i, j+\frac{1}{2}, k+1} ^{n}-\left.E_{y}\right|_{i, j+\frac{1}{2}, k} ^{n}}{\Delta z}-\frac{\left.E_{z}\right|_{i, j+1, k+\frac{1}{2}} ^{n}-\left.E_{z}\right|_{i, j, k+\frac{1}{2}} ^{n}}{\Delta y}\right]
$$

and

$$
\begin{aligned}
\left.E_{x}\right|_{i+\frac{1}{2}, j, k} ^{n+1}=\left.\left(\frac{1-\frac{\Delta t}{\varepsilon} \frac{\sigma}{2}}{1+\frac{\Delta t}{\varepsilon} \frac{\sigma}{2}}\right) E_{x}\right|_{i+\frac{1}{2}, j, k} ^{n}+ & \\
& +\frac{\Delta t}{\varepsilon\left(1+\frac{\Delta t}{\varepsilon} \frac{\sigma}{2}\right)}\left[\frac{\left.H_{z}\right|_{i+\frac{1}{2}, j+\frac{1}{2}, k} ^{n+\frac{1}{2}}-\left.H_{z}\right|_{i+\frac{1}{2}, j-\frac{1}{2}, k} ^{n+\frac{1}{2}}}{\Delta y} \frac{\left.H_{y}\right|_{i+\frac{1}{2}, j, k+\frac{1}{2}-\frac{1}{2}} ^{n}-\left.H_{y}\right|_{i+\frac{1}{2}, j, k-\frac{1}{2}} ^{n+\frac{1}{2}}}{\Delta z}\right] .
\end{aligned}
$$

2) Precision and stability: The FDTD method, like other numerical methods, has the criteria to yield stable and accurate solutions. Precision is understood as the convergence of numerical solution to analytical or experimental solution and stability as finite-amplitude solutions for all $t$. Thus, the parameters that guarantee these criteria are the spatial and temporal increments. To guarantee stability, the time step must satisfy the Courant condition [15] 


$$
\Delta t \leq \frac{1}{v_{\max } \sqrt{\frac{1}{\Delta x^{2}}+\frac{1}{\Delta y^{2}}+\frac{1}{\Delta z^{2}}}},
$$

where $v_{\max }$ is the greatest wave propagation speed in the analysis domain. In order to restrict errors associated with dispersion, ensuring accuracy, spatial increments must satisfy the criteria

$$
\Delta_{x, y, z} \leq \frac{\lambda_{\min }}{10}
$$

where $\lambda_{\min }$ is the shortest wavelength produced by the excitation source [15].

3) Lightning excitation source: In this work, the lightning return stroke current $I(t)$ is represented by the set of equations given by Tanabe [16], which are

$$
I(t)=\left\{\begin{array}{c}
\frac{I_{\max }\left(e^{a_{1} n \Delta t}-e^{a_{2} n \Delta t}\right) \sin ^{2}\left(\omega_{0} n \Delta t\right)}{A_{0}}, n \Delta t \leq 1.5 T_{f} \\
\frac{I_{\max }\left(e^{a_{1} n \Delta t}-e^{a_{2} n \Delta t}\right)}{A_{0}}, n \Delta t>1.5 T_{f} .
\end{array}\right.
$$

In (9), the amplitude was set to $I_{\max }=1 \mathrm{kA}$, the raise and tail times were set to $T_{f}=0.22 \mu \mathrm{s}$ and $T_{t}=$ $139.8 \mu \mathrm{s}$, respectively, and the other constants are given by $a_{1}=0.693147180 / T_{f}, a_{2}=2.5584279 / T_{t}$, $t_{0}=\ln \left(a_{1} / a_{2}\right) /\left(a_{1}-a_{2}\right), A_{0}=e^{a_{1} \cdot t_{0}}-e^{a_{2} \cdot t_{0}}$ and $\omega_{0}=\pi / 3 T_{f}$. Figure 3(a) illustrates the pulse as function of time. Since the maximum frequency of the excitation source is around $400 \mathrm{kHz}$, as shown in Fig.3(b), $\Delta x=\Delta y=\Delta z=0.22 \mathrm{~m}$, which is much less than the minimum wavelength of the excitation source. Thus, errors from numerical dispersion are properly limited.

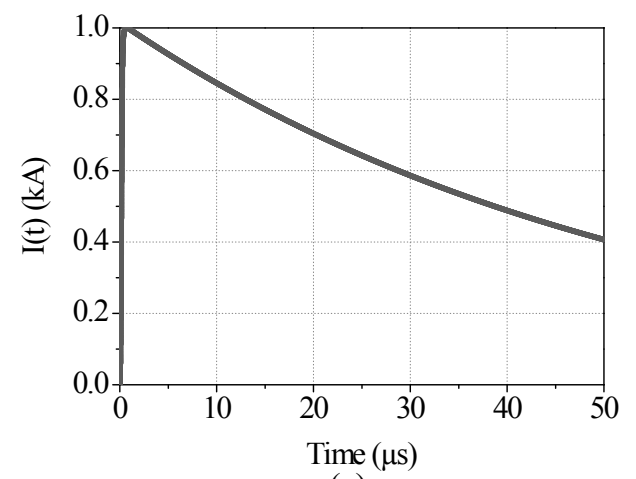

(a)

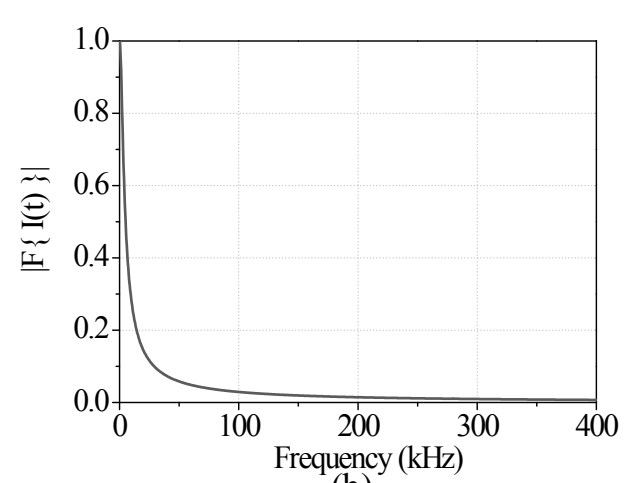

(b)

Fig. 3. Lightning current used as FDTD excitation source: (a) time-domain waveform and (b) normalized Fourier spectrum.

4) FDTD representation of the problem: To simplify data input and facilitating the visualization of the produced vessel model, a graphical interface based on the FDTD method called SAGS (Synthesis and Analysis of Grounding Systems) was used [17]. Uniaxial perfectly matched layer (UPML) [18], [15] was used to truncate the analysis region. To simulate the lightning discharge impinging on the vessel, a FDTD model was conceived with a wooden structure and a metallic roof, based on the description in [4]. The dimensions of the boat modeled in the simulations are given in Fig. 2, in which 
a graphical representation of the FDTD model is also shown. The electromagnetic properties of the materials used in this work are given in Table I and are found in [19], [20]. Electromagnetic properties of the river were measured in [20]. In order to represent the metal covering, a thin metallic plate was modeled in FDTD, as described in [15]. For representing the electrical discharge and its channel, it is used the method described in [17], in which the leader channel is represented by a thin cylindrical conductor parallel to the $z$-axis, starting from the point in which the discharge reaches the boat (the metal plate), up to the cell immediately below the FDTD mesh border, thus entering the UPML region. This way, because of the absorption of the fields around the part of the conductor inside the absorbing region, the conductor can be considered to be virtually infinite in length [21]. At the attachment point, the magnetic field around the conductor is excited, as governed by Ampère's law (2), for implementing the current source.

\begin{tabular}{|c|c|c|c|}
\hline MATERIAL & $\varepsilon_{r}$ & $\sigma(\mathrm{S} / \mathrm{m})$ & $\mu_{r}$ \\
\hline TOCANTINS RIVER WATER & 80 & $46 \times 10^{-4}$ & 1 \\
\hline WOOD & 2 & $4.45 \times 10^{-8}$ & 1 \\
\hline AIR & 1 & 0 & 1 \\
\hline
\end{tabular}

\section{Optimization of BoAt Lightning Protection And Results}

\section{A. FDTD numerical results}

By analyzing the model of Fig. 2(b), which has no lightning protection and is often used in the Amazonian rivers, it is noted that the wooden beams are not good conductors and, thus, it is expected that electric fields are intense inside the watercraft during direct lightning strikes. This is illustrated by Fig. 4(a), which shows the electric field distribution obtained on $y=8.80 \mathrm{~m}$ at $t=30.1 \mu \mathrm{s}$, on a vertical cross-section intercepting the boat and the lightning channel, and by Fig. 5, showing $E_{z}$ obtained $0.8 \mathrm{~m}$ above the floor of the boat over time. Notice that $E_{z}$ intensities in Figures 4 and 5 are due to a $1 \mathrm{kA}$ lightning strike (MV/m for each $\mathrm{kA}$ ). For negative first return strokes (the most common cloud-to-ground lightning in the globe), according to CIGRE, 50\% exceed $30 \mathrm{kA}$. Lightning peak currents for the Amazon region are expected to be moderately higher [22]. 


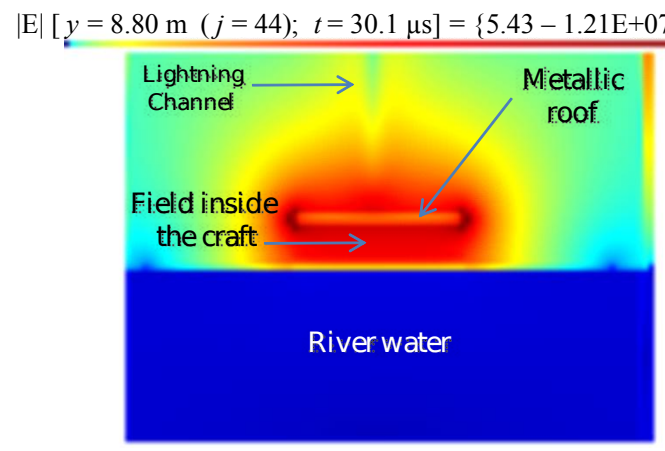

(a)
I E $[y=8.80 \mathrm{~m}(j=44) ; t=33.3 \mu \mathrm{s}]=\{201-4.20 \mathrm{E}+07\} \mathrm{V} / \mathrm{m}$

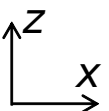

River water

(b)

Fig. 4. Spatial distributions of $|\vec{E}|(y=8.8 \mathrm{~m}, t=30.1 \mu \mathrm{s})$, calculated using the FDTD method, assuming a lightning return stroke with $1 \mathrm{kA}$ of peak current, for (a) the unprotected watercraft and (b) a protected watercraft.

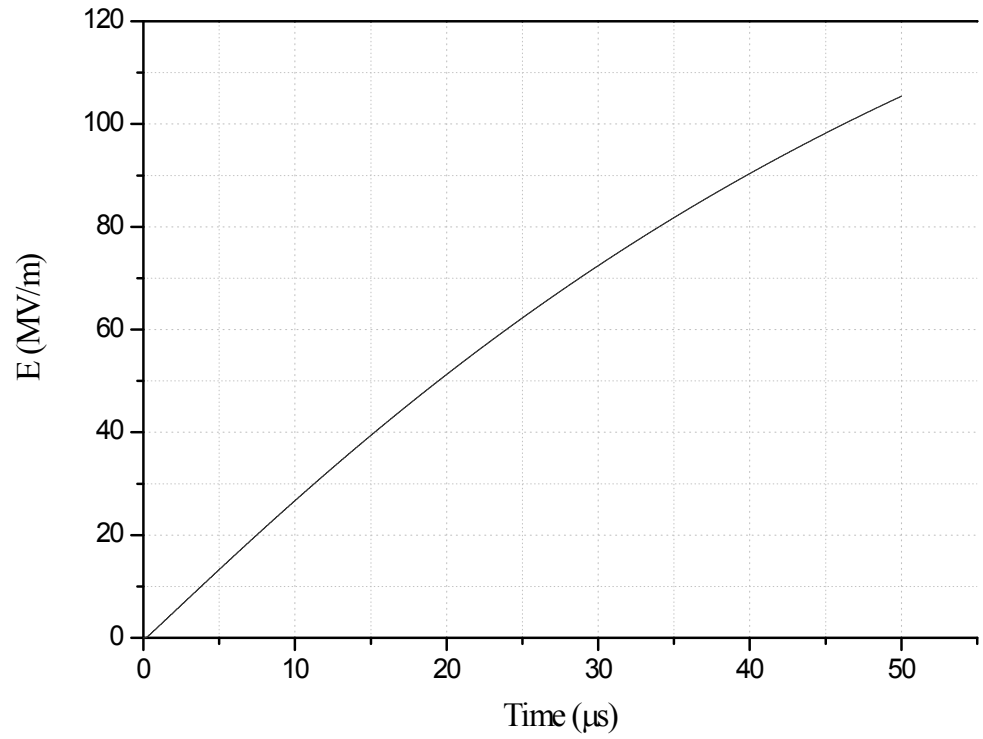

Fig. 5. $E_{z}$ obtained $0.8 \mathrm{~m}$ above the floor of the boat, assuming $1 \mathrm{kA}$ lightning return stroke (air ionization is not considered).

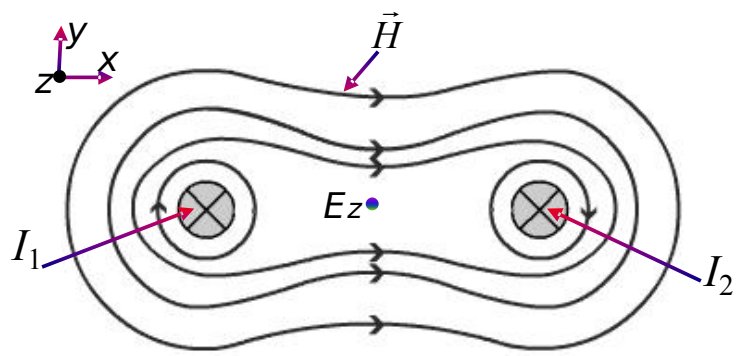

Fig. 6. Magnetic field $\vec{H}$ produced by two parallel rods conducting currents $I_{1}$ and $I_{2}$. $E_{z}$ depends on the circulation of $\vec{H}$, which can be reduced if $I_{1} \approx I_{2}$ inside the boat, where multiple field reflections prevent $E_{z}$ to be zero.

In order to transport charges from the roof to the water, the electrically conductive river water can be exploited by using metal rods connecting the metallic roof to a point beneath the water surface. As a result, the current conducted by a rod produces a magnetic field as given by Ampère's law. Using more than one rod, arranged vertically, parallelly to each other, their respective magnetic fields tend 
Journal of Microwaves, Optoelectronics and Electromagnetic Applications, Vol. 20, No. 2, June 2021 DOI:http://dx.doi.org/10.1590/2179-10742021v20i21074

to be produced in opposite directions, consequently decreasing the $z$-component of the electric field inside the boat (see Fig. 4(b) and Fig. 6). It is difficult in the boat to approximate $E_{z}$ to zero since there are lots of field reflections occurring during the electrodynamic processes described by Maxwell's equations (1) and (2) over time. Therefore, simulations were generated considering several different cases, as seen in the models of Fig. 7: increasing the number of rods per wooden beam and the number of beams with metallic rods.

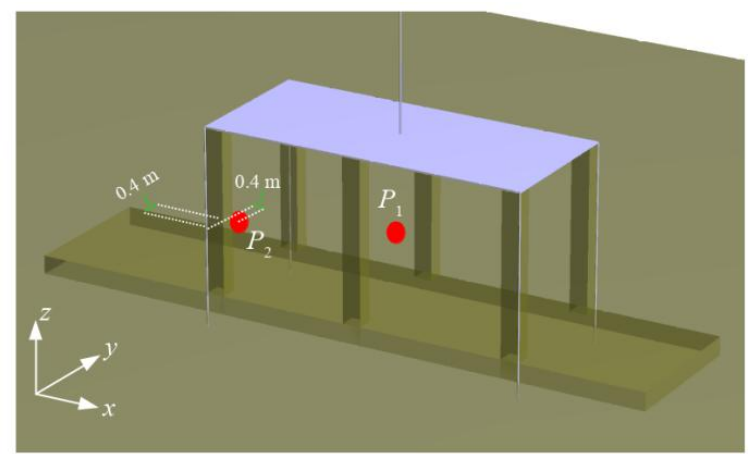

(a)

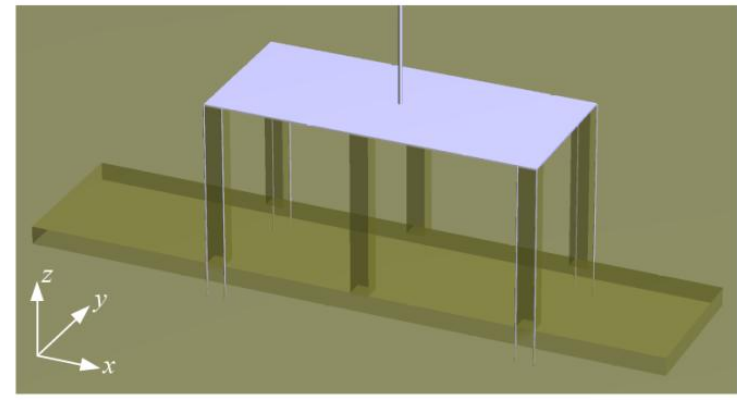

(c)

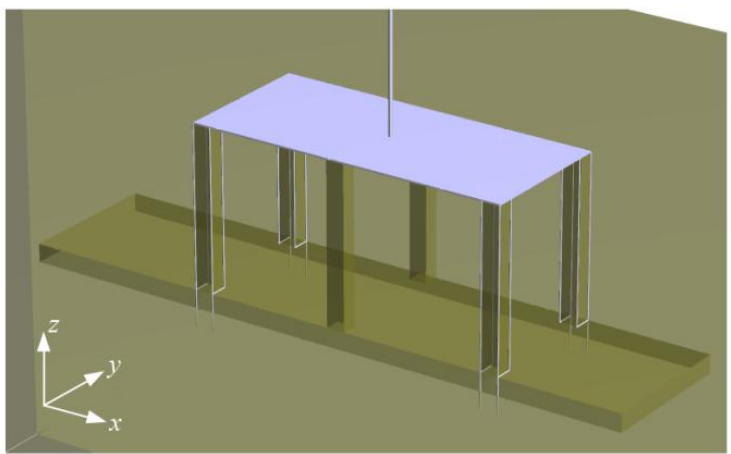

(e)

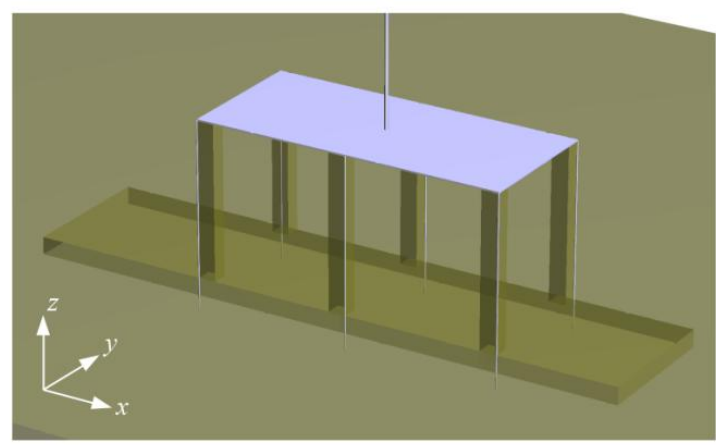

(b)

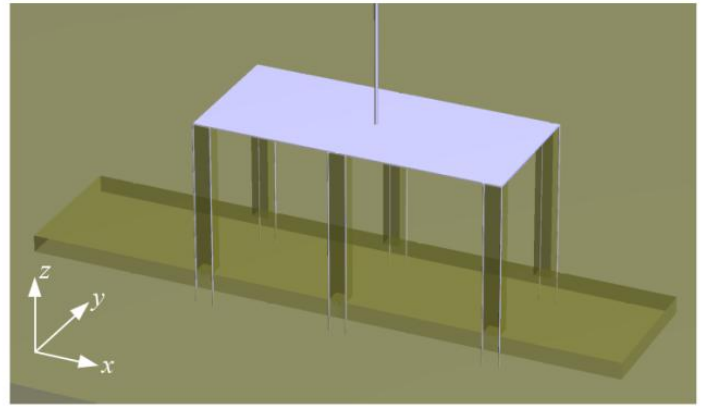

(d)

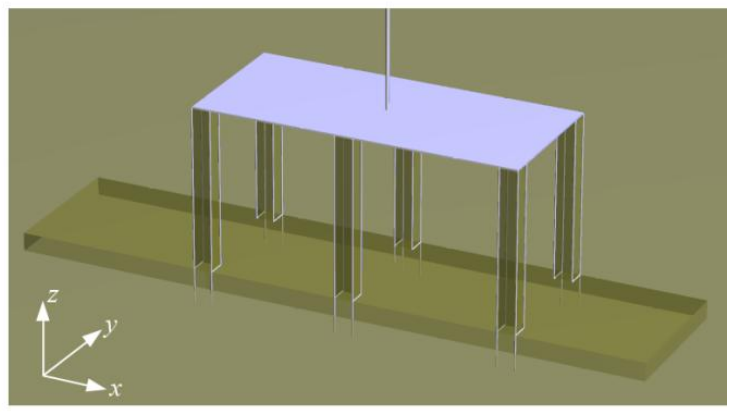

(f)

Fig. 7. FDTD-3D models of proposed protection schemas for the watercraft using: (a) one rod on each of four wooden beams, (b) one rod on each of six beams, (c) two rods on each of four beams, (d) two rods on each of six beams, (e) four rods on each of four beams and (f) four rods on each of six beams.

Observing $E_{z}$ evolution over time in Fig. 8(a), obtained at the point $P_{1}(0.8 \mathrm{~m}$ above the watercraft floor - see Fig. 7(a)), we notice that increasing the number of vertical metallic rods connected to the roof and in contact with water is, in fact, a method that drastically reduces the field intensity inside the 
vessel by a factor of about one hundredth, concerning the case shown in Fig. 5 (non-protected watercraft). The field can be reduced more efficiently by distributing the rods over the perimeter of the watercraft.

Figure 8(b) shows $E_{z}$ calculated near one of the beams (at the point $P_{2}$, as Fig. 7(a) indicates). The inclusion of conductors on each beam has a strong field mitigation capacity in the vicinity of the conductors. Among all cases, maximum reduction of the electric field is observed when 24 conductors are employed on six beams (four conductors per beam). For that specific case, $99.39 \%$ of field reduction was observed with regard to the unprotected model, and $43.60 \%$ was obtained with the protected model using one rod on each of four beams. Percentage field reductions for all analyzed cases are given in Table II.

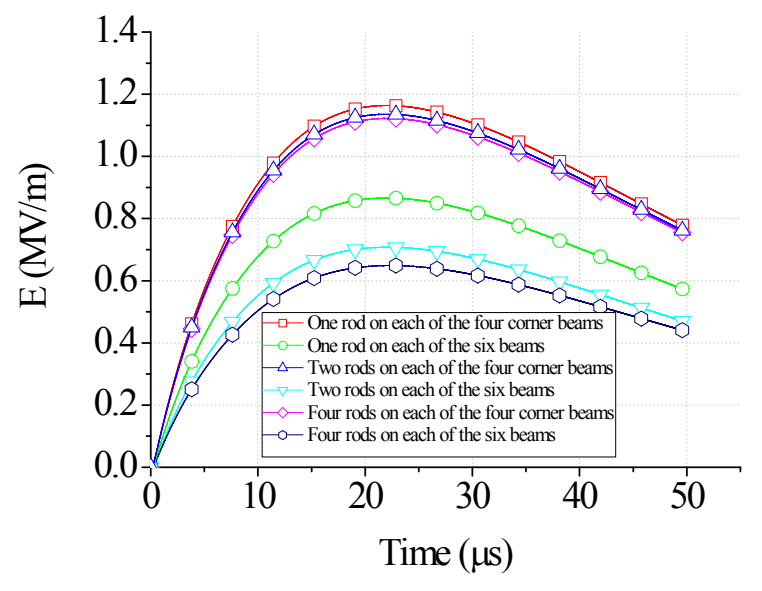

(a)

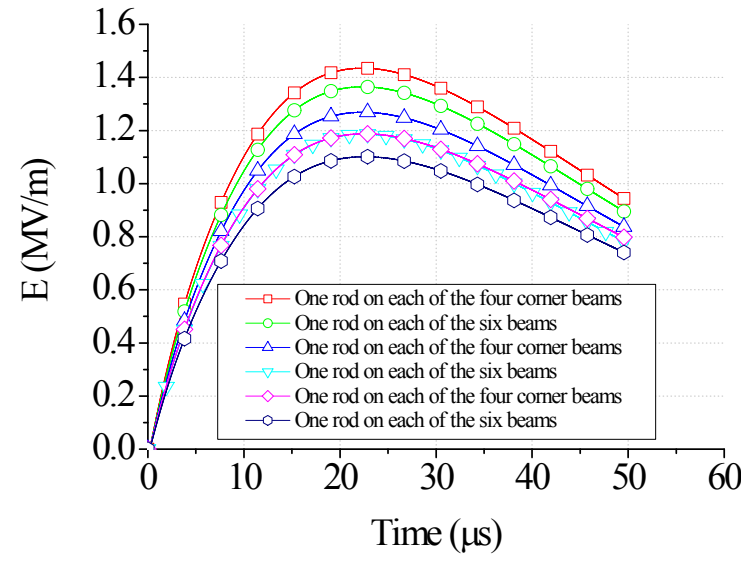

(b)

Fig. 8. Comparison of electric fields of protected models (a) at the geometric center of the watercraft (at the point $\left.P_{1}\right)$ and (b) near a wooden beam with vertical conductors (at the point $P_{2}$ ).

Therefore, adding more rods per beam reduces the electric field inside the geometric center of the watercraft and near the beams due to magnetic field balancing. However, it is impracticable to add so many rods in this watercraft. We found the most cost-effective case the one with two rods on each of the six beams (Fig. 7(d)), for which we estimate an additional weight of about $8.5 \mathrm{~kg}$, which is negligible concerning the total weight of the riverboat. Moreover, adding more metallic parts increases cost, producing minor effects on field reduction as is seen in Fig. 8(a). Figure 9 shows the three-dimensional design of the watercraft with such lightning protection scheme. The local (Belém, PA, Brazil) cost for including this lightning protection was estimated to be between 10 and 20 U.S dollars in February 2020. 


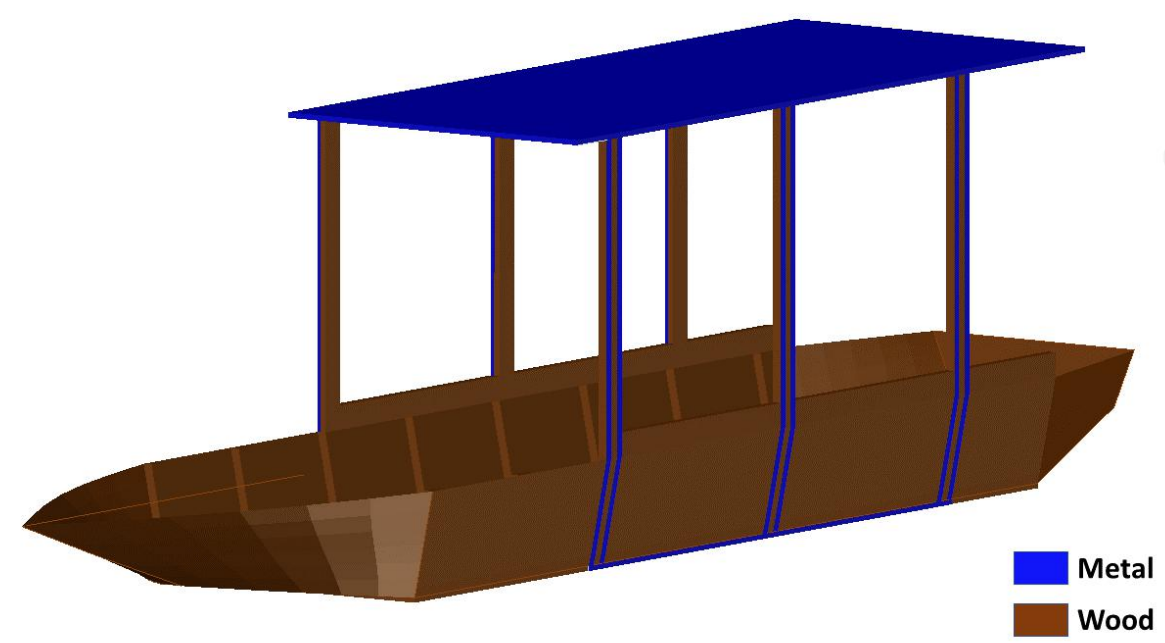

Fig. 9. The most cost-effective lightning protection design proposed to small watercraft in the Amazon region, including two rods per beam.

TABLE II. ELECTRIC FIELD PEAKS AND FIELD PERCENTAGE DECREASES FOR PROPOSED PROTECTION MODELS.

\begin{tabular}{|c|c|c|c|}
\hline $\begin{array}{l}\text { WATERCRAFT LIGHTNING PROTECTION } \\
\text { SCHEMAS }\end{array}$ & $\begin{array}{l}\text { PEAKS OF } E_{z}(\mathrm{MV} / \mathrm{m}) \\
\text { FOR EACH kA OF } \\
\text { LIGHTNING CURRENT }\end{array}$ & $\begin{array}{c}\text { DECREASES OF } E_{Z} \text { WITH } \\
\text { RESPECT TO THE } \\
\text { UNPROTECTED MODEL }(\%)\end{array}$ & $\begin{array}{c}\text { DECREASES OF } E_{Z} \text { WITH } \\
\text { RESPECT TO THE MODEL } \\
\text { USING ONE ROD FOR } \\
\text { EACH OF THE FOUR } \\
\text { BEAMS }(\%) \\
\end{array}$ \\
\hline One Rod On Each Of The Four Beams & 1.14 & 98.92 & 0.00 \\
\hline OnE RoD On Each Of The Six BEAms & 0.85 & 99.19 & 25.26 \\
\hline Two Rods On Each Of The Four Beams & 1.12 & 98.93 & 1.48 \\
\hline Two Rods On Each Of The Six Beams & 0.70 & 99.34 & 38.41 \\
\hline Four Rods On EACH Of THE Four BeAms & 0.11 & 98.95 & 2.69 \\
\hline Four Rods On EACH Of THE SIX BEAMS & 0.64 & 99.39 & 43.60 \\
\hline
\end{tabular}

\section{FinAl REMARKS}

On rivers of the Amazon region, simple watercraft travel daily completely unprotected against lightning events. Frequent lethal incidents have been observed (some of them reported by local media, some not). Overall, there is a lack of knowledge of lightning protection available to watercraft. According to the survey applied in this work and presented in the appendix, $85 \%$ of people have never heard about lightning protection on small riverboats. This way, several watercraft lightning protection schemas have been proposed and analyzed. As long as the vessels consist of wood and usually have metallic roofs, and additionally, rivers in Amazon have considerable electrical conductivity, water has been used for designing lightning protection schemata, consisting of connecting the metallic roofs to the water. The electric field was substantially reduced inside the watercraft with respect to the unprotected ships (99.39\% drop was obtained). However, additional optimization work must be done, 
since high lightning currents can occur in the Amazon region, with the potential, in those cases, to break the electrical insulation of air inside the watercraft. Nevertheless, the proposed protection configurations can prevent air breakdown or reduce currents inside the boat due to air breakdown in cases of high-intensity Amazonian lightning events. Future works will involve the influence of humidity and ionized air.

\section{APPENDIX A}

\section{Survey on lightning safety of boats in the Amazon Region}

A questionnaire survey was conducted in the cities of Ponta de Pedras and Belém, in February 2020. Both cities are in the state of Pará, Brazil. The cities are in the Amazon River delta, about $150 \mathrm{~km}$ from the Atlantic Ocean. The city Ponta de Pedras is located on the second-largest island in South America, which is the $35^{\text {th }}$ largest island in the world (Marajó Island). Over there, it is common to see people living along the shores of the river and using boats as means of locomotion. The only way to go from Belém to Ponta de Pedras is by boat. The questions made during the survey are given in Table A1

TABLE A1. QUESTIONS MADE DURING THE SURVEY REGARDING LIGHTNING SAFETY IN THE AMAZON RIVERS.

\begin{tabular}{cc}
\hline $\begin{array}{c}\text { QUESTION } \\
\text { INDEX }\end{array}$ & QUESTION \\
\hline Q1 & Do you know what is lightning? \\
Q2 & Do you know how to be protected against lightning in a watercraft? \\
Q3 & Have you ever been involved in a lightning accident in a watercraft? \\
Q4 & Have you ever heard of a lightning accident in a watercraft? \\
Q5 & Have you ever heard of lightning struck any watercraft in your region? \\
Q6 & Have you ever heard about lightning protection systems for watercraft? \\
\hline
\end{tabular}

The questionnaire survey was applied to a group of thirty-eight people, in which all of them were men. The interviews were conducted close to the river, in the ports of Belem and Ponta de Pedras. All interviewed people work in some way with activities related to small riverboats. Some of them were the owners of the boats and others worked transporting goods among the cities. The age ranges and the education levels of respondents (who are quantified in percentages) are given in Table A2.

Table A2. Age Ranges and Educational LeVels of the Survey Respondents.

\begin{tabular}{cc}
\hline \multicolumn{2}{c}{ AGE (IN YEARS) } \\
\hline $20-30$ & $21 \%$ \\
$30-60$ & $66 \%$ \\
$>60$ & $13 \%$ \\
\hline EDUCATION LEVEL & \\
\hline Incomplete middle school & $90 \%$ \\
Incomplete high school & $7 \%$ \\
Complete high school & $3 \%$ \\
\hline
\end{tabular}


According to Table A2, the majority of respondents do not have a high educational level. Most of the people did not complete high school and they are adults. All the questions in the survey were Yes/No questions and they are shown in Table A1. The questionnaire started with a basic question about lightning. No deep knowledge regarding lightning physics was asked. Whether the interviewed knew how to recognize a lightning flash or thunder it was enough. Then, it was asked about selfprotection against lightning in watercraft. Whether the respondent claimed to remain inside the watercraft during thunderstorms, it was considered that the interviewer knew how to be protected. According to Table A3, most of the respondents are aware of what lightning is. However, they do not know how to protect themselves during thunderstorms. Specifically, $65 \%$ of people who know what lightning is do not know how to be protected against lightning in watercraft. None of the respondents has ever suffered an accident with lightning on boats.

Regarding question 4 (Q4), only two respondents answered yes. For question 5 (Q5), twelve of them stated that they had heard about lightning accidents in watercraft. For question 6 (Q6), some of the respondents claimed to know about lightning protection for buildings, however, 32 of them have never heard about lightning protection for watercraft. Hence, there is a lack of knowledge on lightning protection available to watercraft and a lack of guidelines for local communities in the Amazon region.

TABle A3. Percentage of ANSWERs to the SURVEY.

\begin{tabular}{ccc}
\hline QUESTION & YES & NO \\
\hline Q1 & $90 \%$ & $10 \%$ \\
Q2 & $31 \%$ & $69 \%$ \\
Q3 & $0 \%$ & $100 \%$ \\
Q4 & $5 \%$ & $95 \%$ \\
Q5 & $22 \%$ & $68 \%$ \\
Q6 & $15 \%$ & $85 \%$ \\
\hline
\end{tabular}

\section{REFERENCES}

[1] F. Albuquerque, "Especialistas alertam para alta incidência de raios durante primavera," Agencia Brasil, 2018. [Online]. Available: http://agenciabrasil.ebc.com.br/geral/noticia/2018-09/especialistas-alertam-para-alta-incidencia-de-raiosdurante-primavera. [Accessed: 02-Oct-2020].

[2] V. A. Rakov and M. A. Uman, Lightning: Physics and Effects. New York: Cambridge University Press, 2003.

[3] C. Morales, J. Neves, and E. Anselmo, "Sferics Timing and Ranging Network - STARNET: Evaluation over South America," in 14th International Conference on Atmospheric Electricity - ICAE, 2011.

[4] E. R. Ferreira, A. F. R. Leal, W. L. N. Matos, G. O. Almeida, R. Shinkai, and M. N. G. Lopes, "Lightning Deaths and Injuries in the Brazilian Amazon Region in the Period of 2009-2019," in 2019 International Symposium on Lightning Protection (XV SIPDA), pp. 1-8, 2019.

[5] R. L. Holle, "A Summary of Recent National-Scale Lightning Fatality Studies," Weather. Clim. Soc., vol. 8, no. 1, pp. 35-42, Jan. 2016.

[6] M. Z. A. A. Kadir, M. A. Cooper, and C. Gomes, "An overview of the global statistics on lightning fatalities," in 2010 30th International Conference on Lightning Protection (ICLP), pp. 1-4, 2010.

[7] E. M. Thomson, "A critical assessment of the US code for lightning protection of boats," IEEE Trans. Electromagn. Compat., vol. 33, no. 2, pp. 132-138, May 1991. 
[8] A. Borghetti and S. Yokoyama, "Lightning protection of power systems," Electr. Power Syst. Res., vol. 85, pp. 1, Apr. 2012.

[9] M. Shintaku, M. Kawakubo, Y. Kishimoto, K. Minakuchi, and A. Ochiai, "Lightning protection in telecommunication buildings," in INTELEC - Twentieth International Telecommunications Energy Conference (Cat. No.98CH36263), pp. 697-702, 1998.

[10] C. Gomes and A. G. Diego, "Lightning protection of communication sites: Revisited," in 2010 30th International Conference on Lightning Protection (ICLP), pp. 1-12, 2010.

[11] M. Loboda, "Lightning Protection of Structures," in Lightning: Principles, Instruments and Applications, Dordrecht: Springer Netherlands, pp. 573-592, 2009.

[12] E. P. Nicolopoulou, I. F. Gonos, and I. A. Stathopulos, "Experimental investigation of the external lightning protection of ships through impulse voltage tests on a scaled-down ship model," IET Sci. Meas. Technol., vol. 10, no. 8, pp. 855865, Nov. 2016.

[13] E. P. Nicolopoulou, I. F. Gonos, and I. A. Stathopulos, "Lightning Induced Overvoltages in the Electric Network of a Ship," in 2018 IEEE International Conference on High Voltage Engineering and Application (ICHVE), pp. 1-4, 2018.

[14] K. Yee, "Numerical solution of initial boundary value problems involving Maxwell's equations in isotropic media," IEEE Trans. Antennas Propag., vol. 14, no. 3, pp. 302-307, May 1966.

[15] A. Taflove and S. C. Hagness, Computational Electrodynamics: The Finite-Difference Time-Domain Method, 3rd ed. Artech House Inc., 2005.

[16] K. Tanabe, "Novel method for analyzing the transient behavior of grounding systems based on the finite-difference time-domain method," in 2001 IEEE Power Engineering Society Winter Meeting. Conference Proceedings (Cat. No.01CH37194), vol. 3, pp. 1128-1132, 2001.

[17] R. M. S. de Oliveira and C. Sobrinho, "Computational Environment for Simulating Lightning Strokes in a Power Substation by Finite-Difference Time-Domain Method," IEEE Trans. Electromagn. Compat., vol. 51, no. 4, pp. 9951000, Nov. 2009.

[18] S. D. Gedney, "An anisotropic perfectly matched layer-absorbing medium for the truncation of FDTD lattices," IEEE Trans. Antennas Propag., vol. 44, no. 12, pp. 1630-1639, 1996.

[19] C. A. Balanis, Advanced Engineering Electromagnetics, 2nd ed., John Wiley \& Sons, Inc.. 2012.

[20] E. S. A. M. Luz, R. M. S. de Oliveira, and P. L. Machado, "Calculation of Lightning-Induced Voltages and Currents on the Transformers Courtyard of Tucuruí Hydroelectric Generation Plant Using the Finite-Difference Time-Domain Method," IEEE Lat. Am. Trans., vol. 14, no. 4, pp. 1600-1611, Apr. 2016.

[21] E. T. Tuma, R. M. S. de Oliveira and C. Sobrinho, "New Model of Current Impulse Injection and Potential Measurement in Transient Analysis of Grounding Systems in Homogeneous and stratified Soils Using The FDTD Method", In: VIII International Symposium on Lightning Protection, 2005.

[22] A. C. Almeida, B. R. P. Rocha, J. R. S. Souza, J. A. S. Sá, and J. A. P. Filho, "Cloud-to-ground lightning observations over the eastern Amazon Region," Atmos. Res., vol. 117, pp. 86-90, Nov. 2012. 